\title{
Meta
}

Journal des traducteurs

Translators' Journal

\section{Chopping down and Reconstructing a Tree}

\section{Janice H. Humphrey}

Volume 42, numéro 3, septembre 1997

L’interprétation en langues des signes

URI : https://id.erudit.org/iderudit/003159ar

DOI : https://doi.org/10.7202/003159ar

Aller au sommaire du numéro

Éditeur(s)

Les Presses de l'Université de Montréal

ISSN

0026-0452 (imprimé)

1492-1421 (numérique)

Découvrir la revue

Citer cet article

Humphrey, J. H. (1997). Chopping down and Reconstructing a Tree. Meta, 42(3), 515-520. https://doi.org/10.7202/003159ar

\section{Résumé de l'article}

Selon qu'ils sont produits en langues vocales ou en langues des signes, les énoncés sont perçus à travers des mécanismes sensibles différents ; il s'agit cependant, dans les deux cas, de langues qui font appel au même processus d'interprétation. Transmettre un sens par le truchement du langage signifie aller au-delà des formes ; c'est aussi arriver à exprimer les aspects affectifs de l'original sans heurter la culture d'arrivée.
Ce document est protégé par la loi sur le droit d'auteur. L’utilisation des services d’Érudit (y compris la reproduction) est assujettie à sa politique d'utilisation que vous pouvez consulter en ligne.

https://apropos.erudit.org/fr/usagers/politique-dutilisation/ 


\title{
CHOPPING DOWN AND RECONSTRUCTING A TREE
}

JANICE H. HUMPHREY

Douglas College, New Westminster, Canada

\begin{abstract}
Résumé
Selon qu'ils sont produits en langues vocales ou en langues des signes, les énoncés sont perçus à travers des mécanismes sensibles différents; il s'agit cependant, dans les deux cas, de langues qui font appel au même processus d'interprétation. Transmettre un sens par le truchement du langage signifie aller au-delà des formes; c'est aussi arriver à exprimer les aspects affectifs de l'original sans heurter la culture d'arrivée.
\end{abstract}

\begin{abstract}
Auditory-aural and visual-gestual languages are perceived through different sensory mechanisms, yet both are languages and in both the process of interpretation is similar. Conveying meaning across languages means going beyond the form; it also means incorporating the affect of a source language utterance in the target language in effective and culturally appropriate ways.
\end{abstract}

When people using different languages and conforming to distinct cultural norms for communication and social interaction seek to exchange ideas and information, an interpreter is required to convey the things that are said in such a way that equivalent social and linguistic meaning is conveyed. This is true whether the individuals involved use spoken languages or signed languages. The discussion below focuses on English and American Sign Language (ASL), however the process of interpretation is similar for both spoken language and sign language interpreters. As well, the process of interpreting between any signed language and any spoken language includes challenges similar to those encountered by individuals working between American Sign Language and English.

\section{THE NATURE OF ENGLISH AND AMERICAN SIGN LANGUAGE}

English and American Sign Language (ASL) are distinct languages which have separate grammatical identities, use words / signs in different ways, and reflect the unique cultural norms of the people groups who use each language. Both languages convey identical kinds of linguistic information and are used to perform the same communicative functions. However, Petitto and Bellugi (1988) note that English and ASL differ in several fundamental ways:

1) each language uses different types of signals to form and express linguistic utterances;

2) the audience receiving the message perceives each language through different sensory mechanisms (auditory-aural vs. visual-gestual);

3) ASL and English handle information differently;

4) different memory structures are used to store and recall each language; and

5) each language is supported by different neutral structures.

As an aural/oral language, English is produced at the rate of approximately five syllables per second or 180 words per minute (Isenhath 1990). ASL, which uses movement 
as the medium of communication and therefore larger physical articulators as compared to those used for the vocal articulation of English, takes roughly double the amount of time to produce a single ASL sign compared to the time required for the utterance of a single English word (Petitto and Bellugi 1988; Petitto 1993, 1994a; Petitto and Marentette 1991). In spite of these differences, ASL transmits information at approximately the same rate as English (Petitto and Bellugi 1988; Klima and Bellugi 1979). This is because each language encodes patterns of rhythm, stress and timing which allow recipients to extract meaning and to predict what the speaker/signer will say next without having to concentrate in too focused a manner on the linguistic utterances being presented (Petitto 1994b, as cited by Mahshie 1995: 114-116; Wilentz 1968).

In order to accomplish this, English uses a combination of functional elements (articles, prepositions, and conjunctions) and content elements (nouns and verbs) in the formation and linear execution of utterances. ASL is composed primarily of content elements. This is true because of the multi-dimensional nature of the visual communication framework within which ASL utterances emerge (Friedman 1976; Klima and Bellugi 1979; Isenhath 1990).

It is important to note that there is an indigenous Sign Language in most countries throughout the world. American Sign Language is the indigenous Sign Language used throughout Anglophone North America. Japanese Sign Language is the natural Sign Language in Japan and French Sign Language is the native Sign Language of France. However, in most countries educators have attempted to create a manual/visual representation of the spoken language of the majority culture. These are not natural languages. They are unable to fully represent the aural/oral language of the majority population and are unable to support communication in the way the indigenous languages do because they are lacking in the visual inflections, rhythm, and patterns which foster one's ability to make sense through a visual language (Mahshie 1995).

\section{THE TASK OF INTERPRETATION}

In order to rise to the task of mediating cross cultural communication, an interpreter must be linguistically facile and socially aware because when an interpreter is introduced into a communication interaction, the basic act of communication itself is affected. Although "the words / signs assigned to communicate our ideas are never an exact replica of the mental information itself" (Moores 1992: 23), a speaker/signer formulates her/his message with a particular goal in mind and crafts the text to accomplish that goal with a particular audience. However, when a message is interpreted, the interpreter receives and analyzes the source language message, rather than the intended recipient. When the interpreter transmits the message, it is received by the intended audience member and is decoded. If the interpretation is successful, the message perceived is the same as that which was sent by the presenter and the presenter's goal is accomplished.

When interpreters are linguistically fluent in their working languages, it is unnecessary for them to attend to the source language message with sustained, focused concentration to determine meaning. This freedom provides interpreters with time to interpret. The way in which effective and accurate interpretation is accomplished has been described in several serialized or sequential process models including those set forth by Seleskovitch (1979), Ingram (1977), Cokely (1985, 1992), and Colonomos (1983, 1984, 1988). According to Humphrey and Alcorn (1995), the basic components of most of those models are similar:

1) cognizant of environmental factors, the interpreter takes in the source language utterance;

2) lexical and semantic units are strung together and held until the interpreter has enough of them to make sense or find meaning in what is being said/signed; 
3) the string of lexical and semantic units (referred to as a "chunk") is analysed to identify the speaker's intent, the goal s/he seeks to accomplish, explicit and implicit ideas, and a multitude of contextual factors which "colour" or impact the meaning of the source language utterance;

4) a mental note is made of the schema and experiential frame brought by both hearing and Deaf consumers and a search must be made for equivalents of cultural norms and cultural overlays of meaning;

5) a search is made of the target language to identify lexical/semantic units and communication behaviours which can be used to produce an utterance in the target language having an equivalent meaning, while maintaining the communication dynamics;

6) after a momentary review of the selected items, the interpretation is expressed in the target language; and

7) the interpreter monitors internal and external feedback to check for errors or needed corrections.

All of this is happening with lightening speed and in a dynamic transactional environment where message revision is inherent.

One analogy used to describe the interpreting process is that of chopping down and then reconstructing a tree (Humphrey and Alcorn 1995). The tree represents the source language, the chopping down or taking apart represents the process of text or message analysis. The branches, twigs, leaves, and chunks of tree trunk are tossed into a river, which represents the mental processing taking place within the interperter's thought processes. On the other end of the river, the pieces are pulled out and the tree is reconstructed - this time into the target language. As the pieces are re-connected, there will be obvious "seams" and almost always some of the leaves and twigs (details) will be lost. In other words, there is no such thing as a perfect interpretation. However, the interpreter will hopefully have identified the tree trunk (main ideas/essentials elements) and the major branches (supporting information) - and will have a TREE in the target language. An interpretation which captures all of the details but misses the main points will be reduced to a "bush" on the other end. An interpretation that conveys an idea different than that of the source language utterance will have a "pile of wood" or a "log cabin" on the other end.

\section{CHALLENGES OF WORKING BETWEEN ENGLISH AND ASL}

The central focus of our work as interpreters is to convey communication of equivalent meaning between people who are linguistically and culturally different. Working between a language constructed to create auditory sense and a language constructed to create visual sense presents several challenges. These include:

1. Making a complete language shift by dropping source language form. When we look at English and ASL we see two languages using very different, yet equally effective, devices to convey meaning. ASL/English interpreters must identify source language meaning and make a complete linguistic shift to express the information in the target language. Failure to drop form results in skewed or unclear communication due to the intrusion of source language elements in target language output (Cokely 1985). This can only be accomplished if the interpreter allows her/himself adequate processing time.

Because English uses both content and functional elements extensively, and ASL uses primarily content elements, interpreters sometimes confuse volume with equivalency. Thus, an interpreter working between English and ASL may find her/himself slipping back toward source language grammatical structure, in order to match the volume of lexical items rather than striving for message equivalency, while maintaining the integrity of the 
target language output. Visual intake of this multitude of signs which matches English volume tires the eyes of the Deaf participants and generally fails to provide equivalent and accessible information. Likewise, truncating spoken English to match ASL in which functional elements are sparsely used, results in unclear and ungrammatical English sentences and misrepresents the linguistic fluency of the Deaf signer.

As interpreters analyze an incoming message, they must be aware of the voice of the linguistic constructions. Analysis of the message requires that the interpreter identify the goal of the signer/speaker, as well. If the speaker/signer is using passive voice in order to be deliberately vague, it is not appropriate for the interpreter to make the message perfectly clear and unambiguous. An example of this is found when working in legal settings. A police officer or lawyer may deliberately ask a question in a vague and general way in order to see what information they can obtain from the individual being interviewed. In such a case, an equivalent lack of specificity needs to be present in the target language interpretation.

Conveying meaning across languages means going beyond the form and identifying the deep structure meaning. When English uses multiple-meaning words and phrases (e.g., make an outline of your presentation), the interpreter needs to drop the form and sign the meaning (e.g., write an outline of your presentation). Likewise, when English combines verbs with prepositions to form new lexical items (e.g., make an outline of your presentation), the interpreter should drop the literal form (out - as in outside; line - as in a long thin mark) and sign the intended meaning.

Similarly, interpreters need to know how to use generic with non-specific referents in both English and ASL (e.g., there are certain times in a person's life when..., or they say being in love is wonderful) and where it is clear in the subtext what the referent is, providing that specific information in the ASL interpretation. When hearing a compact lexical item in English (e.g., drugs), the interpreter needs to convert that to an appropriate noun-listing in ASL and when seeing a noun-listing in ASL, the interpreter needs to convert that to a compact lexical item in English.

A final example would be when Deaf and hearing individuals come together to share something in narrative form. A Deaf individual usually begins a narration by taking time to develop the scene, identify the participants, and follows by conveying the action and information in a highly descriptive way. This often violates the norms for setting up an English narration. It is imperative that interpreters develop techniques to mediate the amount of detail in linguistically appropriate ways.

2. Incorporating cultural norms. Since interpretation generally occurs in a majority language/culture environment and ASL interpreters tend to be members of the majority (hearing) language/culture, it is a challenge for interpreters to resist the urge to subscribe to hearing norms of time, turn-taking, greeting and leave-taking, as well as a multitude of other culturally linked behaviours. Further, the way one expresses humour, makes a point, agrees or disagrees with another, changes the topic, or performs any other speech act is guided by cultural norms for social and communicative interaction which are specific to each language group.

Basic things such as showing respect for the individual one is speaking with and getting another's attention vary widely. In the majority culture of Canada and the United States, using the other person's name is one way to accomplish both of these social and communicative tasks. One may say, "Mary,..." at which point Mary will look up or respond to indicate that you have her attention. As the speaker continues, $s /$ he will insert Mary's name to indicate sincerity, desire to make a psychological connection or as a way to demonstrate respect toward her: "I was wondering, Mary, if you would come to the meeting a bit early today." 
If one interprets from English to ASL without changing the way names are used in the target language/culture, the Deaf participant may react negatively toward the hearing participant because their cultural sense of being respected has been violated. Thus, because of a decision made on the part of the interpreter (or ignorance of one's options and obligations), the communication event becomes skewed and may fail to accomplish the goals of the individuals involved.

The use of visual versus auditory emotive elements is a challenge to interpreters working between spoken languages and signed languages. In the mainstream society of Canada and the U.S., it is considered impolite to "make faces." Thus children are taught from a very young age not to stare, point, or gape, much less duplicate another person's characteristics or behaviours. Because of the visual display of affect in ASL, signers are sometimes viewed negatively by hearing people who are unaware that facial affect markers are a mandatory part of ASL communication. This is exacerbated when the high degree of direct address and resultant role-shifting in ASL frequently requires that the interpreter visually convey the behaviours and feelings of multiple characters. Interpreters need to recognize these differences, but they should not allow the target language output to be diminished in clarity or essential affective information as a result. The absence of visual affect markers in ASL results in a monotone-type of presentation which fails to captivate an audience and is often not true to the intent of the speaker.

Thus, interpreters working between ASL and English must incorporate the affect being conveyed in effective and culturally appropriate ways. This includes conveying information that may be conveyed only by affect markers, but which clearly contain information. In North American English, for example, most affective markers are invisibly conveyed via vocal inflection. In the case of indicating an intensifier such as "really" some registers require the speaker to make a comment and accompany it with a slow sideto-side shake of the head (e.g.: Wow! Is he good looking!). Not only must the EnglishASL interpreter change the auditory affect into a visual one, $s /$ he must remember to change the movement of the head from a side-to-side movement to an up-and-down nod. If the interpreter is unaware of this phenomenon, $\mathrm{s} /$ he may incorporate the head movement from hearing culture norms and use them in such a way as to negate the very statement being made (e.g.: Wow! is he good looking: [with side-to-side head movement] means he is quite ugly).

Another cultural phenomenon which impacts interpretation is that of linguistic registers. Most languages have ways through which they may manipulate content to fit into more formal and less formal settings and to create varying degrees of psychological and interpersonal distance or closeness. Joos (1967) refers to this as the five clocks, including intimate, informal, consultative, formal, and frozen. It is imperative for interpreters to identify the linguistic register(s) being used by the source language presenter and to accurately incorporate the corresponding markers and/or behaviours in their interpretation. In ASL, for example, the more formal the linguistic register, particular lower-face grammatical markers are adjusted to reduce the width of an open mouth. If the interpreter fails to make this seemingly minor adjustment, Deaf participants may feel insulted or "talken down to" by the hearing communicator when it is in fact an interpreter error or oversight. The consequences could damage the success of the goal of one or both participants, increase the psychological and cultural distance, and skew communication.

\section{CONCLUSION}

The linguistic and cultural differences of the parties for whom an interpreter is working require interpreters to constantly monitor the accuracy of their perception of source language/culture and the integrity of language/culture output in the target language. This 
means they must take time, not only to receive and analyze the source language utterance, but to produce the target language in culturally appropriate and grammatically correct form. When working between English and ASL, it is easy for interpreters whose first language is English to slip into their native language grammatical structure and to conform to hearing culture norms and behaviours, particularly in the presence of an emotionally charged environment, a complex or difficult text, rapid source language production or a topic which is unfamiliar to the interpreter. This is even more challenging when working in oneon-one or small group interaction where the speakers change rapidly and the task at hand changes from ASL as the source language with the target language English, to English as the source language and ASL as the target language. Thus, the challenge - and the joy — of being an interpreter.

\section{REFERENCES}

COKELY, D. (1985): Towards a Sociolinguistic Model of the Interpretation Process: Focus on ASL and English, Ph.D. dissertation, Georgetown University, Washington (DC).

COKELY, D. (1992): Interpretation: A Sociolinguistic Model, Burtonsville (MD), Linstok Press (Dissertation Series).

COLONOMOS, B. (1980, 1983, 1984, 1987, 1988): Interpreting Process: A Working Model, Unpublished papers.

FRIEDMAN, L. (1976): "The Manifestation of Subject, Object, and Topic in American Sign Language", Charles (Ed.), Subject and Topic, New York, Academic Press.

HUMPHREY, J. and B. ALCORN (1995): So You Want to be an Interpreter? An Introduction to Sign Language Interpreting, Amarillo (Texas), H \& H Publishers.

INGRAM, R. (1978): "Sign Language Interpretation and General Theories of Language, Interpretation and Communication", Gerver and Sinaiko (Eds.), Language Interpretation and Communication, New York, Plenum Press, NATO Conference Series, Series III: Human Factors, pp. 109-118.

ISENHATH, J. (1990): The Linguistics of American Sign Language, Jefferson (NC), McFarland \& Company, Inc. JOOS, M. (1967): The Five Clocks, New York, Harbinger Books.

KLIMA, E. and U. BELLUGI (1979): The Signs of Language, Cambridge (MA), Harvard University Press.

MAHSHIE, S. (1995): Educating Deaf Children Bilingually, Washington (DC), Pre-College Programs, Gallaudet University.

MARMOR, G. and L. PETITTO (1979): "Simultaneous Communication in the Classroom: How Well is English Grammar Represented?", Sign Language Studies, 23, pp. 99-136.

MOORES, D. (1992): "What do we Know and When did we Know it?", Walworth, Moores and O'Rourke (Eds.), A Free Iland: Enfranchising the Education of Deaf Children, Silver Spring (MD), T.J. Publishers, pp. 67-88.

PETITTO, L. (1993): "On the Otogenetic Requirements for Early Language Acquisition", Boysson-Bardies, de Schonen, Jusczyk, MacNeilage and Morton (Eds.), Developmental Neurocognition: Speech and Face Processing in the First Year of Life, Kluwer Academic Press, pp. 365-383.

PETITTO, L. (1994a): "On the Equipotentiality of Signed and Spoken Language in Early Language Ontogeny: What we have Learned since the Congress of Milan", Snider (Ed.), Post-Milan ASL and English Literacy: Issues, Trends, and Research - Keynote Address, Washington (DC), Gallaudet University College for Continuing Education, pp. 195-224

PETITTO, L. (1994b): as cited by Mahshie (1995: 1 14-116).

PETITTO, L. and U. BELLUGI (1988): "Spatial Cognition and Brain Organization: Clues from the Acquisition of a Language in Space", Stiles-Davis, Kritchevsky and Bellugi (Eds.), Spatial Cognition: Brain Bases and Development, Hillsdale (NJ), Lawrence Erlbaum Associates.

PETITTO, L. and P. MARENTETTE (1991): "Babbling in the Manual Mode: Evidence for the Ontogeny of Language", Science, 251, pp. 1496-1498.

SELESKOVITCH, D. (1978): Interpreting for International Conferences: Problems of Language and Communication, Washington (DC), Pen and Booth.

SELESKOVITCH, D. (1992): "Fudamentals of the Interpretive Theory of Translation", Plant-Moeller (Ed.), Expanding Horizons, Proceedings of the 12th National Convention of the Registry of Interpreters for the Deaf, Silver Spring (MD), RID Publications.

WILENTZ, J. (1968): The Senses of Man, New York, Thomas Y. Crowell. 